\title{
Pharmacy practice research methods
}

\section{Zaheer-Ud-Din Babar (Ed): Adis/Springer International Publishing, Switzerland, 2015, ISBN 978331914671 3. Official price in Europe: $€ 105.99$ (includes VAT), Ebook: $€ 83.30$}

\author{
J. W. F. van Mil ${ }^{1}$
}

Received: 3 May 2015/Accepted: 9 May 2015/Published online: 19 May 2015

(C) Koninklijke Nederlandse Maatschappij ter bevordering der Pharmacie 2015

There are many books about research methodologies, some less detailed and some more detailed. Most of these books focus on a specific field in society, sociology, psychology and health care. In healthcare, again, there are books and papers with research methodologies available. Although such materials may also be useful in pharmacy practice research (PPR), certain aspects of pharmacy are just not properly covered by the existing publications. This book fills the gap.

And the first chapter, by Christine Bond, tells you why this gap needs filling. In an excellent exposé she writes about the necessity of pharmacy practice research, as part of health services research. She explains why this type of research is so timely, and why evidence and evidence based pharmacy practice are needed. In the second chapter, Parastou Donyai takes you through the different methodologies of the book with great insight. In the next two chapters, the essence of qualitative and quantitative research are discussed. And from Chapter 5 onwards the methods and concepts are outlined, often illustrated with examples from published studies.

Is this the ultimate book about PPR? No it is not. The book focusses on especially qualitative research, and is clearly written from a social pharmacy perspective. Quantitative aspects of PPR receive relatively little attention, although in practice, the quantitative aspects of research in pharmacy practice seems to be more outspoken. The description of pharmacoepidemiology is somewhat limited, as is the description of the international modelling for health economic studies. There is relatively little

\footnotetext{
J. W. F. van Mil

jwfvmil@vanmilconsultancy.nl

1 Margrietlaan 1, 9471 CT Zuidlaren, The Netherlands
}

attention for the broad field of implementation research, and its many different models and schools.

Looking at the author list, it is noteworthy that almost all authors (apart from the Danes) have an Anglosaxon background, or come from the English research tradition such as the authors from Qatar. There are no authors from Latin and other countries that currently also produce research in the field of pharmacy practice such as France, Spain, Brazil, China or Japan. The research tradition in such countries is different, and they might have valuable additions to a book like this. On the other hand, due to language differences, they often publish in non-English journals, and the names of the key-people are relatively unknown.

\section{Conclusion}

This very interesting book offers a very good read, but it is not a reference book. Especially the first two chapters are worth reading repeatedly, and advocate the field of pharmacy practice research very well. The level of detail about certain qualitative methods is such, that the book is helpful in setting up such studies. Other chapters will give the arguments and background for other, much needed, pharmacy practice research.

If you really would like support in setting up a study, more detailed books or articles are needed, but this book definitely gives you an understanding what pharmacy practice research is all about and where and how to start. 